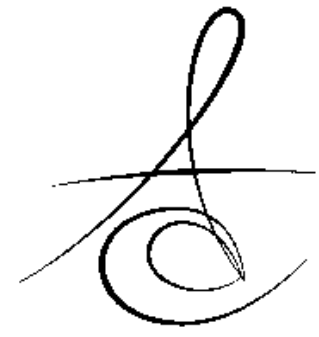

\section{TEMPOROMANDİBULAR EKLEM RAHATSIZLIKLARINDA OKLUZAL FAKTÖRLERİN DEĞERLENDİRİLMESİ}

\author{
EVALUATION OF OCCLUSAL FACTORS IN TEMPOROMANDIBULAR JOINT \\ DISORDERS
}

\author{
Dr. Öğr. Üyesi İpek İşCAN*
}

Makale Kodu/Article code: 3460

Makale Gönderilme tarihi: $\quad 06.06 .2017$

Kabul Tarihi; 15.02 .2018

\section{öz}

Amaç: Bu araştırmanın amacı okluzal faktörler ile temporomandibular eklem (TME) rahatsızlıkların ilişkisinin incelenmesidir.

Materyal ve Metod: Çene yüz ağrıları kliniğine art arda gelen hastaların kayıtları retrospektif olarak incelendi. TME rahatsızlıkları için araştırma tanı kriterleri (ATK/TME) kullanılarak TME rahatsızlığı tanısı konuldu. Angle sınıflaması, anterior ve lateral rehberlik faktörleri belirlendi. Ki- kare ve Continuity Yates düzeltmesi kullanılarak verilerin niteliksel karşılaştırması yapıldı.

Bulgular: TME rahatsızlığı teşhisi konulan bireylerde kanin koruyuculu okluzal rehberliğine eklem rahatsızlığı bulunmayanlardan daha fazla oranda rastlanıldı. Myofasiyal ağrı teşhisi konulan bireylerde anterior rehberlik varlığı, disk deplasmanı teşhisi konulan bireylerde Angle Sınıf I molar ilişkisi, artraljisi bulunanlarda ise kanin koruyuculu okluzyon diğer alt gruplardan daha fazla oranda tespit edildi.

Sonuç: Sonuç olarak seçilmiş okluzal faktörlerle temporomandibular eklem rahatsızlıkları arasında ilişki bulunmuştur.Temporomandibular eklem rahatsızlıkları değerlendirilirken bu faktörler göz önünde bulundurulmalıdır ancak temporomandibular rahatsızlıkların etyolojisinin multifaktöriyel olduğu unutulmamalıdır Anahtar Kelimeler: Okluzyon, Malokluzyon, Temporomandibular eklem.

\section{ABSTRACT}

Aim: The aim of the study was to investigate the relation between main occlusal factors and temporomandibular disorders.

Material and Methods: Records of patients attending orofacial pain clinic were screened retrospectively. The diagnosis of temporomandibular disorders were made according to research diagnostic criteria for temporomandibular disorders (RDC/TMD). Angle classification, the type of occlusal guiding pattern were determined. Chi-square and Yates's continuity correction were used to compare qualitative data.

Results: Canine guided occlusion were found more frequently in subjects with temporomandibular disorders than in subjects without temporomandibular disorders. It was also observed that prevalance of anterior guidance in subjects with myofacial pain, Angle Class I molar relation in subjects with disc displacement, canine guidance occlusion in subjects with artraljia was higher than other subgroups of temporomandibular disorders.

Conclusion: In conclusion, it was found that there is an association between selected occlusal factors and temporomandibular disorders. Meanwhile, multifactorial etiology should be kept in mind while evaluating impact of occlusal factors on temporomandibular disorders.

Keywords: Occlusion, Malocclusion, Temporomandibular joint.

\footnotetext{
* Serbest Dişhekimi, İstanbul.

${ }^{* *}$ Medipol Üniversitesi, Diş Hekimliği Fakültesi Protetik Diş Tedavisi A.D. İstanbul.
} 


\section{Gíriş}

TME rahatsızlıkları, sadece TME ve çiğneme kaslarından kaynaklanan problemleri değil, aynı zamanda çiğneme sisteminin fonksiyonu ile ilgili bozuklukların tümünü kapsamaktadır. $^{1}$ En önemli klinik bulgu ve belirtileri TME bölgesinde ağrı, alt çene hareketinde ve/veya çiğneme fonksiyonunda sınırlama ya da düzensizlik ve TME sesleridir. ${ }^{2}$

TME rahatsızlıklarının etyolojisi konusunda literatürde henüz bir fikir birliği bulunmamakla birlikte multifaktöriyel olduğu düşüncesi kabul görmektedir. Okluzyon, travma, stres, derin sabit ağrılar, parafonksiyonel aktiviteler ana faktörler arasında yer almaktadır. $^{1}$

Okluzal faktörler, araştırmalarda TME hastalıklarında hazırlayıcı, başlatıcı ya da devam ettirici faktör olarak düşünülmüştür. ${ }^{3}$ Nöromusküler teori okluzal faktörlerle ilgili en yaygın teoridir. Bu teori, okluzal çatışmaların proprioseptif geri bildirimi yoluyla nöromusküler mekanizmada dengesizlik yaratarak ağrı ve spazma neden olacağını ileri sürer. ${ }^{4}$

Malokluzyon, okluzyonun fonksiyonel ve estetik olarak istenilen düzeyde olmayıp, idealden sapmasıdır. ${ }^{5}$ Malokluzyon, morfolojik ve fonksiyonel olarak incelenmektedir. Morfolojik malokluzyon dişler arası statik anatomik ilişkideki anomaliyi tanımlarken, fonksiyonel malokluzyon ise bireyin çene hareketleri esnasında okluzal form ve/veya çeneler arası ilişkinin uyumsuzluğunu anlatır. ${ }^{6}$

Literatürde okluzyonun TME rahatsızlıklarına etkisinin \%10-15 olduğu bildirilmektedir. ${ }^{7}$ TME rahatsızlıkları ile okluzal faktörlerin rolünü araştıran çalışmaların bazılarında TME hastalıkları bulgu ve belirtileri ile Angle sınıflaması ${ }^{8-12}$ ve okluzal rehberlik faktörleri ${ }^{13-16}$ arasında pozitif ilişki saptanırken, bazı araştırmalarda herhangi bir ilişkiye rastlanılmamıştır. ${ }^{17-23}$ Ancak malokluzyonun TME rahatsızlıklarına yol açan en önemli faktör olduğu düşüncesi ile geçmişte olduğu gibi günümüzde de geri dönüşümsüz okluzal düzenlemeler diş hekimleri tarafından yapımaktadır. Bu araştırmanın amacı, TME rahatsızlıklarında seçilmiş okluzal faktörlerin dağıımı ve bu rahatsızlıklarla ilişkisinin var olup olmadığının belirlenmesidir. Bu araştırmanın hipotezi "Belirli okluzal faktörler ile TME rahatsızlıkları arasında bir ilişki bulunmaktadır." olarak belirlenmiştir.

\section{MATERYAL VE METOD}

$\mathrm{Bu}$ çalışmada özel bir diş kliniğinin çene yüz ağrıları merkezine 2015 -2016 Ağustos tarihleri arasında art arda başvuran hastaların kayıtları retrospektif olarak incelendi. Bu çalışma İstanbul Medipol Üniversitesi Klinik araştırmalar etik kurulu tarafından (10840098-604.01.01-E.35572) onaylandı. Molar desteği olmayan, hareketli protez kullanan, ortodontik tedavi yaptıran, anterior ve/veya posterior diş protetik tedavi işlemi yaptıran hastalar araştırma dışı bırakıldı. Çalışmamızda belirlenen okluzal faktörler aşağıdaki şekilde kayıt edildi:

A) Sagital yöndeki diş ilişkisi; Angle sınıflamasına göre Sınıf I,II ve III olarak belirlendi. Angle sınıflamaları sağ 1. molar dişlerin intermaksiller ilişkisine göre yapıldı.1. molar diş eksikliğinde ise kanin dişler rehber alındı.

B) Okluzal rehberlikler; Hastadan alt çenesini maksimum interkuspal pozisyondan sağa ve sola kaydırması istenerek yan anterior rehberlik kaydedildi. Bu hareket esnasında yalnızca kaninler temas ediyorsa kanin koruyucu okluzyon, kanin ile birlikte bir veya daha fazla azı dişi temasta ise gurup fonksiyonu okluzyon olarak kabul edildi. Hasta alt çenesini öne kaydırdığında ön dişlerin teması var ise "Anterior rehberlik var" yok ise "Anterior rehberlik yok" olarak kaydedildi.

C) Dengeleyen taraf çatışma ve kontak varlığı; Hasta dişlerini sağa veya sola kaydırdığında dengeleyen tarafta diş teması oluyorsa "Dengeleyen taraf kontak", çalışan taraftaki teması ortadan kaldıracak şekilde dengeleyen taraf diş teması oluyorsa "Dengeleyen taraf çatışma" olarak kabul edildi. Kontak ve çatışmaların tespitinde 8 mikron $(\mu)$ baush artikülasyon kağıtları kullanıldı.

TME muayenesi bu konuda uzman tek bir hekim tarafından yapıldı. TME rahatsızlıkları tanısı temporomandibular rahatsızlıklarda araştırma tanı kriterleri (TMR/ATK) kullanılarak yapıldı. ${ }^{24}$ TMR/ATK' de hasta standart kriterler kullanılarak fiziksel ve psikolojik olarak iki ana bölümde değerlendiril- mektedir. Bu araştırmada hastanın eklem rahatsızlığının fiziksel değerlendirilmesinin yapıldığı 1 . bölüm kullanıldı. Bu bölüm sonucunda hastalara miyofasiyal ağrı , disk deplasmanı ya da Artralji tanılarından biri konuldu. Bu araştırmada hastaya bu tanılardan herhangi birisi konulduysa hastada "TME rahatsızlığı var" olarak kabul edildi. 
Çalışmada elde edilen bulgular değerlendirilirken, istatistiksel analizler için IBM SPSS Statistics 22 (IBM SPSS, Türkiye) programı kullanıldı. Çalışma verileri değerlendirilirken tanımlayıcı istatistiksel metodların (Ortalama, Standart sapma, frekans) yanısıra niteliksel verilerin karşılaştırılmasında Ki-Kare testi ve Continuity yates düzeltmesi kullanıldı. Anlamlılık $p<0.05$ düzeyinde değerlendirildi.

\section{BULGULAR}

Çalışma 2015-2016 Ağustos ayları arasında yaşları 13 ile 70 arasında değişmekte olan, 85'i erkek (\%28.9) ve 209'u kadın (\%71.1) olmak üzere toplam

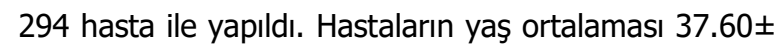
13.07 idi. Çalışmamızda kullanılan parametrelerin dağılımları Tablo-1'deki gibidir.

Tablo 1. Çalışma parametrelerinin dağılımları

\begin{tabular}{llll}
\hline & & $\mathbf{n}$ & $\%$ \\
\hline Temporomandibular & Var & 228 & 77,6 \\
rahatsızlık & Yok & 66 & 22,4 \\
\hline Disk deplasmanı & Var & 172 & 58,5 \\
& Yok & 122 & 41,5 \\
\hline Miyofasiyal Ağrı & Var & 109 & 37,1 \\
& Yok & 185 & 62,9 \\
\hline \multirow{2}{*}{ Artralji } & Var & 94 & 32,0 \\
& Yok & 200 & 68,0 \\
\hline Angle sınıflaması & Angle sınıf I & 259 & 88,1 \\
& Angle sınıf II & 25 & 8,5 \\
& Angle sınıf III & 10 & 3,4 \\
\hline Lateral okluzal rehberlik & Kanin koruyuculu & 154 & 52,4 \\
& Grup fonksiyonu & 87 & 29,6 \\
& Dengeleyen tarak & 22 & 7,5 \\
& kontak & 31 & 10,5 \\
\hline Anterior rehberlik & Dengeleyen taraf & 33 & 18,0 \\
& Yok & 241 & 82,0 \\
\hline & Varma & & \\
& & & 5 \\
\hline
\end{tabular}

TME rahatsızlığı olan ve olmayan hastalar arasında Angle sınıflaması ve anterior rehberlik açısından istatistiksel olarak anlamlı bir farklılık bulunamadı. ( $p>0.05)$.

Lateral okluzal rehberlik oranları açısından ise TME rahatsızlığı olan ve olmayan hastalar arasında istatistiksel olarak anlamlı farklılık bulundu. ( $p: 0.014$; $\mathrm{p}<0.05)$. TME rahatsızlığı olan hastalarda kanin koruyuculu (\%54.4) ve dengeleyen taraf çatışma (\%12.7) görülme oranları yüksekken, TME rahatsılığı olmayan hastalarda grup fonksiyonu (\%39.4) ve dengeleyen taraf kontak (\%12.1) görülme oranlarının yüksek olduğu görüldü.(Tablo-2)
TME rahatsızlıklarının alt gruplarına göre çalışma parametreleri incelendiğinde ise miyofasiyal ağrısı olan hastalarda anterior rehberlik görülme oranı (\%87.2), miyofasiyal ağrısı olmayan hastalardan (\%75.6) istatistiksel olarak anlamlı düzeyde yüksek bulundu. ( $\mathrm{p}: 0.040 ; \mathrm{p}<0.05)$. Disk deplasmanı olan hastalarda ise Angle sınıflaması açısından Angle Sınıf I (\%91.3) görülme oranı, disk deplasmanı olmayan hastalardan (\%82.1) anlamlı düzeyde yüksek bulundu (p:0.009; $p<0.05)$.

Artraljisi olan ve olmayan hastalar arasında lateral okluzal rehberlik dağılım oranları açısından istatistiksel olarak anlamlı farklılık kaydedildi.(p:0.012; $\mathrm{p}<0.05)$ Artraljisi olan hastalarda kanin koruyuculu fonksiyonel okluzyon görülme oranı (\%60.6), artraljisi olmayan hastalardan (\%50) anlamlı düzeyde yüksek olarak belirlenirken, artraljisi olmayan hastalarda dengeleyen taraf kontak görülme oranı (\%10.4), artraljisi olan hastalardan $(\% 0)$ anlamlı düzeyde yüksek bulundu. (Tablo-3)

\section{TARTIŞMA}

$\mathrm{Bu}$ araştırmada belirli okluzal faktörlerin TME bozukluğu olan hastalarda dağılımı ve ilişkisi incelendi. Daha önce yapılmış araştırmalarla ${ }^{25-27}$ uyumlu olarak hastaların yarıdan fazlası kadın olarak saptandı. (\%60) Çene eklemi rahatsızlıklarının kadınlarda daha fazla görülmesini Luther $^{27}$ hormonal faktörlere bağlamıştır.

Araştırmamız sonucu elde edilen bulgular bazı okluzal faktörlerin TME rahatsızlıkları ile ilişkili olduğunu göstermiş ve çalışmamızın hipotezi kabul edilmiştir. Çalışmamızda statik okluzyon incelemesinde Angle Sınıf I okluzyonun TME hastalık teşhisi konulan (\%89) ve konulmayan bireylerde (\%84) oldukça yüksek oranda bulunduğu görülmüştür. İki grup arasında istatistiksel olarak anlamlı bir fark bulunamamıştır. Ancak TME rahatsızlıklarının alt gruplarına baktığımızda disk deplasmanı olan hastalarda Angle 1 molar ilişkisi diğer alt gruplara oranla anlamlı derecede yüksek bulunmuştur. Daha önce yapılan araştırmalarda bu konuda farklı sonuçlar rapor edilmiştir. Angle sınıflaması ile TME rahatsızlıkları arasında ilişki varlığının incelendiği araştırmalarında, Perry ${ }^{8}$ ve Loisella ${ }^{9}$, Angle Sınıf II molar ilişkisinin TME rahatsızlıklarında daha sık görüldüğünü rapor etmiştir.

Pullinger ve ark. ${ }^{17}$, Angle Sınıf II bölüm II molar ilişkisine sahip bireylerde kas ve eklem hassasiyetlerine 
Tablo 2. TME rahatsızlığı varlığına göre Angle sınıflaması, Lateral ve Anterior rehberlik parametrelerinin değerlendirilmesi

\begin{tabular}{|c|c|c|c|}
\hline & \multicolumn{2}{|c|}{ Temporomandibular rahatsızlık } & \multirow{3}{*}{$\mathbf{p}$} \\
\hline & Yok $(n=66)$ & $\operatorname{Var}(n=228)$ & \\
\hline & n (\%) & n (\%) & \\
\hline \multicolumn{4}{|l|}{ Angle sınıflaması } \\
\hline Angle sınıf I & $56(\% 84,8)$ & $203(\% 89)$ & \multirow{3}{*}{0,386} \\
\hline Angle sınif II & $6(\% 9,1)$ & $19(\% 8,3)$ & \\
\hline Angle sınıf III & $4(\% 6,1)$ & $6(\% 2,9)$ & \\
\hline \multicolumn{4}{|l|}{ Lateral okluzal rehberlik } \\
\hline Kanin koruyuculu & $30(\% 45,5)$ & $124(\% 54,4)$ & \multirow{4}{*}{$0,014 *$} \\
\hline Grup fonksiyonu & $26(\% 39,4)$ & $61(\% 26,8)$ & \\
\hline Dengeleyen tarak kontak & $8(\% 12,1)$ & $14(\% 6,1)$ & \\
\hline Dengeleyen taraf çatışma & $2(\% 3,0)$ & $29(\% 12,7)$ & \\
\hline \multicolumn{4}{|l|}{ Anterior rehberlik } \\
\hline Yok & $10(\% 15,2)$ & $43(\% 18,9)$ & \multirow{2}{*}{0,611} \\
\hline Var & $56(\% 84,8)$ & $185(\% 81,1)$ & \\
\hline
\end{tabular}

Tablo 3. TME rahatsızlıkları alt gruplarına göre Angle sınıflaması, Lateral ve Anterior rehberlik parametrelerinin değerlendirilmesi

\begin{tabular}{|c|c|c|c|c|c|c|}
\hline & \multicolumn{2}{|c|}{ Miyofasiyal ağrı } & \multicolumn{2}{|c|}{ Disk Deplasmanı } & \multicolumn{2}{|c|}{ Artralji } \\
\hline & Yok $(n=119)$ & $\operatorname{Var}(\mathrm{n}=109)$ & Yok $(n=56)$ & $\operatorname{Var}(n=172)$ & Yok(n=134) & $\operatorname{Var}(n=94)$ \\
\hline & \multicolumn{2}{|c|}{$\mathrm{n}(\%)$} & \multicolumn{2}{|c|}{$\mathrm{n}(\%)$} & \multicolumn{2}{|c|}{$\mathrm{n}(\%)$} \\
\hline $\begin{array}{l}\text { Angle } \\
\text { sinıflaması } \\
\text { Angle sınıf I } \\
\text { Angle sınıf II } \\
\text { Angle sınif III }\end{array}$ & $\begin{array}{l}96(\% 89,7) \\
7(\% 6,5) \\
4(\% 3,7)\end{array}$ & $\begin{array}{l}89(\% 88,1) \\
10(\% 9,9) \\
2(\% 2)\end{array}$ & $\begin{array}{l}46(\% 82,1) \\
10(\% 17,9) \\
0(\% 0)\end{array}$ & $\begin{array}{l}157(\% 91,3) \\
9(\% 5,2) \\
6(\% 3,5) \\
\end{array}$ & $\begin{array}{l}123(\% 91,8) \\
7(\% 5,2) \\
4(\% 3,0)\end{array}$ & $\begin{array}{l}80(\% 85,1) \\
12(\% 12,8) \\
2(\% 2,1)\end{array}$ \\
\hline & $\mathrm{p}=0.711$ & & $\mathrm{p}=0.005^{*}$ & & $p=0.122$ & \\
\hline
\end{tabular}

\begin{tabular}{|c|c|c|c|c|c|c|}
\hline $\begin{array}{l}\text { Lateral } \\
\text { Okluzal } \\
\text { Rehberlik }\end{array}$ & & & & & & \\
\hline $\begin{array}{l}\text { Kanin } \\
\text { koruyuculu }\end{array}$ & $61(\% 51,3)$ & $63(\% 57,8)$ & $35(\% 62,5)$ & $89(\% 51,7)$ & $67(\% 50,0)$ & $57(\% 60,6)$ \\
\hline $\begin{array}{l}\text { Grup } \\
\text { fonksiyonu }\end{array}$ & $37(\% 31,1)$ & $24(\% 22,0)$ & $17(\% 30,4)$ & $44(\% 25,6)$ & $36(\% 26,9)$ & $25(\% 26,6)$ \\
\hline $\begin{array}{l}\text { Dengeleyen } \\
\text { tarak kontak }\end{array}$ & $8(\% 6,7)$ & $6(\% 5,5)$ & $2(\% 3,6)$ & $12(\% 7,0)$ & $14(\% 10,4)$ & $0(\% 0)$ \\
\hline $\begin{array}{l}\text { Dengeleyen } \\
\text { taraf çatışma }\end{array}$ & $13(\% 10,9)$ & $16(\% 14,7)$ & $2(\% 3,6)$ & $27(\% 15,7)$ & $17(\% 12,7)$ & $12(\% 12,8)$ \\
\hline & $p=0.397$ & & $p=0.074$ & & $\mathrm{p}=0.012 *$ & \\
\hline $\begin{array}{l}\text { Anterior } \\
\text { Rehberlik } \\
\text { Yok } \\
\text { Var } \\
\end{array}$ & $\begin{array}{l}29(\% 24,4) \\
90(\% 75,6)\end{array}$ & $\begin{array}{l}14(\% 12,8) \\
95(\% 87,2)\end{array}$ & $\begin{array}{l}6(\% 10,7) \\
50(\% 89,3)\end{array}$ & $\begin{array}{l}37(\% 21,5) \\
135(\% 78,5)\end{array}$ & $\begin{array}{l}27(\% 20,1) \\
107(\% 79,9)\end{array}$ & $\begin{array}{l}16(\% 17,0) \\
78(\% 83,0)\end{array}$ \\
\hline & $\mathrm{p}=0,040 *$ & & $p=0.110$ & & $p=0.673$ & \\
\hline
\end{tabular}


daha fazla rastladıklarını bildirmişlerdir. Ancak, eklem sesleri ve Angle sınıflaması ile TME rahatsızlıkları arasında bir ilişki bulamamışlardır. Pullinger ve Seligman ${ }^{10}$ 'Redüksiyonlu disk deplasmanı', 'Redüksiyonsuz disk deplasmanı', 'TME hikayesi bulunan osteoartroz (primary osteoartroz)', 'TME hikayesi olmayan osteoartroz' ve 'Miyalji' olmak üzere 5 gruptan oluşan deney grubu (215 kişi) ve TME rahatsızlıkları bulgu ve belirtisi bulunmayan kontrol grubu (107 kişi) ile yaptıkları araştırmalarında Angle Sınıf II bölüm I ve Sınıf I molar ilişkilerinin primary osteoartroz grubunda kontrol grubundan daha yüksek oranda bulunduğunu bildirmişlerdir. Tsolka ve ark. ${ }^{11} 75$ semptomatik ve 28 asemptomatik bireyi klinik olarak ve kinesiografi ile değerlendirmişlerdir. Temporomandibular eklem hasta grubunda, Sınıf II bölüm I malokluzyonun kontrol grubuna göre daha yüksek oranda görüldüğünü rapor etmişlerdir. Selaimen ve ark. ${ }^{12}$, 72 deney ve 30 kişilik kontrol grubunda, overbite, overjet, angle sınıflamasının da bulunduğu okluzal faktörlerin, temporomandibular rahatsızlık geliştirmedeki rollerini araştırmışlardır. Bu araştırma sonucunda Sınıf II malokluzyon TME rahatsızlıkları geliştirme açısından riskli bulunmuştur.

Roberts ve ark. ${ }^{18}$ ise 1988 yılında yaptıkları araştırmada eklem içi rahatsızlıkları bulunan TME hastaları ile asemptomatik bireyler arasında molar ilişkileri açısından farklııı bulamamışlardır. Runge ve ark. ${ }^{19}$, ortodontik tedavi öncesi 226 bireyde eklem sesleri ile okluzyon arasındaki ilişkiyi değerlendirmişlerdir. Çalışmanın sonucunda, statik ve fonksiyonel okluzyon ile eklem sesleri arasında ilişki bulamamışlardır. Al Hadi ${ }^{20}$, 600 semptomatik ve asemptomatik bireylerde yaptığı araştırmada TME hastalarında Angle sınıflaması açısından fark bulamamıştır. Yılmaz ve ark. $^{21} 150$ öğrenci ile yaptıkları araştırmalarında malokluzyon ile TME rahatsıılıkları arasında ilişki bulamamıştır.

Okluzal rehberliğin kas aktivitelerini etkileyebileceği rapor edilmesine rağmen herhangi bir rehberliğin TME rahatsızlıklarını önlediği kanıtlanamamıştır. ${ }^{28}$ Çalışmamızda TME hastalarında kanin koruyuculu okluzyon ve dengeleyen taraf çatışma yüksek oranda bulunurken hasta olmayan bireylerde grup fonksiyonu ve dengeleyen taraf kontak daha fazla oranda görülmüştür. TME rahatsızlıklarının alt gruplarından artralji hastalarında kanin koruyuculu okluzyonun (\%60.6) artraljisi olmayanlarda ise dengeleyen taraf kontak (\%10.4) görülme oranının diğer alt gruplara oranla istatistiksel olarak anlamlı derecede yüksek olduğu görülmektedir. Bu sonuçlar Minagi ve ark.'nın ${ }^{13}$ rapor ettiği sonucu destekler biçimdedir. Minagi ve ark. ${ }^{14}$ çalışmayan taraf çatışma ile eklem sesleri ve eklemin dik yönde hareketi arasındaki ilişkiyi inceledikleri araştırmalarında çalışmayan taraf kontağın aslında bir koruma mekanizması olduğu sonucuna varmışlardır. Donegon ve ark. ${ }^{22}$ asemptomatik bireylerde kanin koruyuculu okluzyon prevalansını \%32, semptomatik hastalarda ise \%22 olarak bildirmiştir. Çalışmamız sonuçları ile birlikte değerlendirildiğinde, bu araştırma kanin koruyuculu okluzyonun kişiyi TME rahatsızlığı geliştirmekten koruyamayacağını göstermektedir. Aksine, bazı araştırmalar ise kanin koruyuculu okluzyon eksikliğinin TME rahatsızlığı geliştirilmesi açısından risk faktörü olduğunu rapor etmişlerdir. ${ }^{12,15}$ Diğer bazı araştırmalarda ${ }^{18,19,23}$ ise, okluzal rehberliğin TME rahatsızlıkları üzerinde bir etkisi bulunmadığını rapor edilmiştir. Butler ve ark. ${ }^{23} 56$ hasta ile yaptıkları araştırmada yan okluzal rehberlik ile eklem sesleri ve kas hassasiyetleri arasında bir ilişki bulamamıştır. Roberts ve ark. ${ }^{18}$ disk deplasmanı bulunan ve normal disk pozisyonu bulunan bireyleri karşılaştırdıkları araştırmalarında okluzal rehberlik açısından fark bulamamıştır. Runge ve ark. ${ }^{19}$ ortodonti öncesi 226 bireyde yaptıkları araştırmada eklem sesleri ile okluzyon arasındaki ilişkiyi değerlendirmişlerdir. Çalışan veya çalışmayan taraf kontaklar ile eklem sesleri arasında herhangi bir ilişki bulamamışlardır.

Anterior rehberlik sağlıkı bir stomatognatik sistemde aranan özelliklerden birisidir. Ön diş rehberliği, alt çenenin öne hareketi esnasında ön grup alt ve üst diş ilişkisinin posterior dişlerin disokluzyonunu sağlaması olarak tarif edilebilir. ${ }^{16}$ Costa ve ark. ${ }^{16}$ 2012'de 100 hastada yaptıkları araştırmada TME hastalarında anterior rehberlik oranını \%74 bulurken asemptomatik bireylerde \%36 olarak bildirmişlerdir. Çalışmamızda bu araştırmadan farklı olarak TME rahatsızlığı bulunan (\%81) ve bulunmayan bireylerde (\%84) yüksek oranda anterior rehberlik rapor edilmiştir. İki grup arasında anlamlı bir fark bulunamamıştır. Bu farklıı̆ın TME rahatsızlığı teşhis kriterlerinin farklılığına ve araştırmadaki hasta sayısının farklıığına bağlamaktayız. TME rahatsızlıkları alt gruplarına baktığımızda miyofasiyal ağrılı hastalarda anterior rehberlik görülme oranının $(\% 87,2)$ diğer TME rahatsızlığı alt gruplarından $(\% 75,6)$ anlamlı derecede yüksek 
olduğunu görüyoruz. Bu farklılığın nedeni olarak ön rehberlik varlığının yanı sıra ön dişlerin dikey ve yatay yöndeki ilişkilerinin önem kazandığını düşünmekteyiz.

Araştırmamızda TMR /ATK kriterleri kullanılmıştır. Bu teşhis kriterleri Temporomandibular Eklem rahatsızlıkları teşhisinde araştırmalar için kullanılan en güncel yöntemdir. Ancak araştırmamız retrospektif bir araştırma olup kesitsel veriler sunduğundan dolayı TME rahatsızıkları ile okluzal faktörler arasında neden sonuç ilişkisi kurulamamıştır. Bu konuda yapılacak kontrollü randomize ve uzun takip süresine sahip çalışmalara ihtiyaç vardır.

\section{SONUÇ}

Okluzal faktörler ve TME rahatsızlıkları arasındaki ilişki yıllardır tartışmalıdır ve henüz literatürde bu konuda bir fikir birliği sağlanamamıştır. Çalışmamızda TME rahatsızlığı bulunan bireylerde kanin koruyuculu okluzyon ve dengeleyen taraf kontak, bulunmayan bireylerde ise grup fonksiyonu ve dengeleyen taraf kontak daha fazla bulunmuştur. TME alt gruplarında da Angle sınıflaması ve okluzal rehberlik açısından farklılıklara rastlanmıştır. Sonuçta, TME hastalıklarının multifaktoriyel etyolojiye sahip olduğu ve belirli bir okluzal faktörün TME rahatsızlığına neden olacağının kesin bilimsel kanıtı henüz olmadığı göz önünde bulundurularak TME hastalıklarına yaklaşılmalıdır.

Neslihan Tınastepe:ORCID ID: 0000-0002-4688-8653 İpek İşcan: ORCID ID: 0000-0002-5728-9971

\section{KAYNAKLAR}

1. Okeson JP. Management of temporomandibular disorder and occlusion. Sixth Edition. Mosby Elsevier: 2008. 7-9,26,164.

2. Clark GT, Delcanho RE, Goulet JP. The utility and validity of current diagnostic procedures for defining temporomandibular disorder patients. Adv Dent Res 1993;7:97-11.

3. De Boever JA, Carlsson GE, Klineberg IJ. Need for occlusal therapy and prosthodontic treatment in the management of temporomandibular disorders. Part I.Occlusal interferences and occlusal adjustment. J Oral Rehabil 2000;27:367-379.

4. Suvinen TI, Reade PJ,Kemppainen P, Könönen M, Dworkin SF. Review of aetiological concepts of temporomandibular pain disorders.Towards a biopsychosocial model for integration of physical disorder factors with psychological and psychosocial illness impact factors. Eur J Pain 2005;9:613-33.

5. Houston WJB, Stephens CD,Tulley WJ.The scope of orthodontic practice.In Houston WJB, Stephens $C D$, Tulley WJ, eds. A textbook of Orthodontics.Oxford: Butterworth-Heinemann 1992: 1-13.

6. Ahlgren J, Posselt $O$. Need of functional analysis and selective grinding in orthodontics: A clinical and electromyographic study. Acta Odontol Scand 1963; 21:187-217.

7. Celi'c R, Jerolimov V, Panduri'c J. A study of the influence of occlusal factors and parafunctional habits on the prevalence of signs and symptoms of TMD. Int J Prosthodont 2002;15:43-48.

8. Perry HT Jr. Relation of occlusion to the temporomandibular joint dysfunction: the orthodontic viewpoint. J Am Dent Assoc 1969; 79: 137-41.

9. Loiselle RJ. Relation of occlusion to the temporomandibular joint dysfunction: the prosthodontic viewpoint. J Am Dent Assoc 1969; 79: 145-6.

10. Pullinger AG, Seligman DA. Overbite and overjet characteristics of refined diagnostic groups of temporomandibular disorder patients.Am J Orthod Dentofacial Orthop 1991; 100:401-15.

11. Tsolka P, Walter JD, Wilson RF, Preiskel HW. Occlusal variables, bruxism and temporomandibular disorders: a clinical and kinesiographic assessment. J Oral Rehabil 1995;22:849.

12. Selaimen CMP, Jeronymo JCM, Brilhante DP, Lima EM, Grossi Márcio L, Grossi PK. Occlusal Risk Factors for Temporomandibular Disorders. Angle Orthod 2007;77:471-77.

13. Minagi $S$, Watanabe $H$, Sato $T$, Tsuru $H$. The relationship between balancing-side occlusal contact patterns and temporomandibular joint sounds in humans: proposition of the concept of balancing side protection. J Craniomandib Disord 1990;4:251-6.

14. Minagi $S$, Ohtsuki $H$, SotoT, Ishii $A$. Effect of balancing-side occlusion on the ipsilateral TMJ dynamics under clenching. J Oral Rehab 1997;1:57-62. 
15. Rinchuse DJ, Kandasamy S, Sciote J. A contemporary and evidence-based view of canine protected occlusion. Am J Orthod Dentofacial Orthop 2007; 132:90-102.

16. Costa MD, Froes Junior GRT, Santos CN. Evaluation of occlusal factors in patients with temporomandibular joint disorder. Dental Press ] Orthod 2012;17:61-8.

17. Pullinger AG, Seligman DA, Solberg WK. Temporomandibular disorders. Part III:Occlusal factors associated with temporomandibular joint tenderness and dysfunction. J Prosthet Dent 1988;59: 483-489.

18. Roberts CA, Katzberg RW, Tallents RH, Espeland MA, Handelman SU. Correlation of clinical parameters to the arthrographic depiction of temporomandibular joint internal derangements. Oral Surg Oral Med Oral Pathol 1988;66:32-6.

19. Runge ME, Sadowsky C, Sakols EI., BeGole A. The relationship between temporomandibular joint sounds and malocclusion. Am J Orthod Dentofacial Orthop 1989; 96:36-42.

20. al-Hadi LA. Prevalence of temporomandibular disorders in relation to some occlusal parameters. J Prosthet Dent 1993;70:345-50.

21. Yılmaz AB, Yeşil Durmuş Z. TME düzensizlikleri semptomlarına dişhekimliği fakültesi öğrencileri arasında rastlanma sıklığı ile cinsiyet, maloklüzyon ve parafonksiyonel alışkanlıkların ilişkisinin tespit edilmesi. Atatürk Diş Fak Der 2002;12:14-19

22. Donegan SJ, Christensen LV, McKay DC. Canine tooth guidance and temporomandibular joint sounds in non-patients and patients. J Oral Rehabil 1996; 23:799-804.

23. Butler JH, Folke LE, Bandt CL. A descriptive survey of signs and symptoms associated with myofascial pain-dysfunction syndrome. J Am Dent Assoc 1975; 90:635-9.

24. Dworkin SF, LeResche L: Research diagnostic criteria for temporomandibular disorders: review, criteria, examinations and specifications, critique. J Craniomandib Disord 1992;6:301-355.

25. Huang GJ, Leresche L, Critchlow CW, Martin MD, Drangsholt MT. Risk factors for diagnostic subgroups of painful temporomandibular disorders (TMD). J Dent Res 2002;81:284-8.
26. John MT, Dworkin SF, Mancl LA. Reliability of clinical temporomandibular disorder diagnoses. Pain 2005;118:61-9.

27. Luther F. TMD and occlusion part II. Damned if we don't? Functional occlusal problems: TMD epidemiology in a wider context. $\mathrm{Br}$ Dent J 2007;202:38-9.

28. Belser UC, Hannam AG. The influence of altered working-side occlusal guidance on masticatory muscles and related jaw movement. J Prosthet Dent 1985;53:406-13.

\section{Yazışma Adresi}

Dr.Neslihan Tınastepe

Ataşehir Bulvarı,

Manolya2/13, Ataşehir/İstanbul

e-mail:neslihantinastepe@hotmail.com 